\title{
Maternal and Fetal Outcomes in Severe Preeclampsia with Acute Lung Edema in Dr. Soetomo General Hospital in 2018-2019
}

\author{
Yohanis Timang ${ }^{1}$, Ernawati $^{2}$ \\ ${ }^{1}$ E-mail: yohanismd@gmail.com \\ ${ }^{1}$ Department of Obstetrics and Gynecology, Dr. Soetomo Hospital, Faculty of Medicine of Universitas Airlangga, Surabaya, Indonesia. \\ ${ }^{2}$ Maternal-Fetal Medicine, Department of Obstetrics and Gynecology, Dr. Soetomo Hospital, Faculty of Medicine of Universitas Airlangga, \\ Surabaya, Indonesia.
}

\begin{abstract}
Background: Pulmonary edema in severe preeclampsia is a serious problem because it requires intensive care and has poor maternal and infant outcomes, especially in developing countries. Objective: To understand risk factors, maternal and fetal outcomes in severe preeclampsia patients with acute pulmonary edema. Methods: This study is a descriptive analytic study, using case report data of patients with preeclampsia with acute pulmonary edema at dr. Soetomo General Hospital Surabaya during 2018 to 2019. Result: During 2018 - 2019 the prevalence of severe preeclampsia cases was $29 \%$ of the total deliveries, while acute pulmonary edema occurred in $17.2 \%$ of severe preeclampsia cases. More than $50 \%$ of cases were found in patients younger than 35 years, with a mean maternal age of 31.7 years. The highest gestational age was more than 34 weeks ( $45 \%$ of cases) and was dominated by multiparas (70.3\%). $81 \%$ cases of pulmonary edema occur in antepartum, and $48 \%$ of them require intensive care with a ventilator. Most cases (61.5\%) were delivered by cesarean section. The mean birth weight of infants born was $2265 \pm 815$ grams with a first minute APGAR score $\geq$ was recorded in $72.3 \%$ of cases. On the outcome of severe preeclampsia with pulmonary edema, maternal mortality was $8.1 \%$ and infant mortality was $5 \%$. Conclusion: The prevalence of acute pulmonary edema in patients with severe preeclampsia is $17.2 \%$, occurs mostly in antepartum phase with gestational age more than 34 weeks and most cases requires intensive care with a ventilator.
\end{abstract}

Keywords: severe preeclampsia, lung edema, ventilator

\section{Introduction}

Acute pulmonary edema is an emergency condition, characterized by accumulation of fluid in the lung tissue and alveoli which causes impaired gas exchange and decreased lung compliance, causing clinical manifestations such as dyspnea and hypoxia (Purvey and Allen, 2017). Acute pulmonary edema that occurs during pregnancy can be caused by various etiologies, including preeclampsia or eclampsia, use of tocolytic drugs, comorbidities in the form of cardiovascular disease, and cardiovascular disorders that occur during pregnancy (Karamchandani, Bortz and Vaida, 2016).

Severe preeclampsia and eclampsia are the main causes of acute pulmonary edema in pregnancy, with $0.6 \%$ to $5 \%$ of patients with preeclampsia/eclampsia experiencing acute pulmonary edema (Pordeus et al., 2018). In Indonesia, preeclampsia is still the second highest contributor to maternal mortality (Wardhana, Dachlan and Dekker, 2018). The incidence of preeclampsia in Dr. Soetomo General Hospital in 2013-2014 was 1106 cases, of which 5.6\% had pulmonary edema (Setiawan, Airlangga and Rahardjo, 2019). Acute pulmonary embolism also has a strong association with fluid administration in patients planned for cesarean section, induction of labor, or prophylactic administration of magnesium sulfate in preeclamptic patients. The diagnosis of acute pulmonary embolism is based on clinical examination, but the underlying etiology of acute pulmonary edema is generally difficult to determine (Pordeus et al., 2018). Pulmonary edema is also a major cause of Intensive Care Unit (ICU) admission and in more critical situations, mechanical ventilation may be required. ICU admission and mechanical ventilation have also been shown to contribute to an increase the duration of hospitalization and an increase in the financing burden. This is a problem, especially in countries with limited health insurance (Wardhana, Dachlan and Dekker, 2018).

Pulmonary edema in pregnancy can be caused by various etiologies. Physiological changes during pregnancy, such as increased plasma volume and decreased plasma oncotic pressure are some of the predisposing factors for pulmonary edema. Severe preeclampsia, characterized by systemic endothelial dysfunction, increased vascular resistance, and increased capillary permeability, causes excessive fluid extravasation that can lead to pulmonary edema. Severe proteinuria and systemic inflammation can also cause a decrease in serum albumin and
IJRP 2021, 91(1), 196-204; doi:10.47119/IJRP1009111220212600 
plasma oncotic pressure. Oliguria and elevated serum creatinine due to kidney damage can also increase sodium and water retention. These conditions lead to an increased risk of pulmonary edema in preeclampsia patients (Wardhana, Dachlan and Dekker, 2018).

\section{Methods}

This research is a descriptive analytic study. Data collection was carried out using medical records of patients with severe preeclampsia with acute pulmonary edema at dr. Soetomo General Hospital Surabaya from 2018 to 2019. Based on the patient's medical records, the total deliveries from 2018 to 2019 were 2968 patients. Total deliveries with severe preeclampsia were 859 and 148 experienced acute pulmonary edema. Data analysis in this study was carried out using Pearson correlation statistical analysis to determine the relationship between characteristics and outcomes of severe preeclampsia patients with pulmonary edema status. Then a chi square comparison test was conducted to analyze the differences in characteristics and outcomes between subjects with mechanical ventilation and without mechanical ventilation.

\section{Results}

Based on the data from dr. Soetomo General Hospital, during 2018 to 2019, the number of deliveries obtained was 2968 patients. Of all deliveries carried out in 2018 to 2019, the incidence of severe preeclampsia was 859 cases $(28.9 \%)$, with $148(17.2 \%)$ of whom had acute pulmonary edema (Table 1$)$.

Table 1. Number of cases

\begin{tabular}{lccc}
\hline Year & Total Deliveries $(\boldsymbol{\%})$ & $\begin{array}{c}\text { Severe preeclampsia } \\
(\boldsymbol{\%})\end{array}$ & $\begin{array}{c}\text { Severe preeclampsia } \\
\text { with acute lung } \\
\text { edema }(\boldsymbol{\%})\end{array}$ \\
\hline $\mathbf{2 0 1 8}$ & $1522(51,3)$ & $379(44,1)$ & $45(30)$ \\
$\mathbf{2 0 1 9}$ & $1446(48,7)$ & $480(55,9)$ & $105(70)$ \\
Total & $\mathbf{2 9 6 8 ( 1 0 0 )}$ & $\mathbf{8 5 9}(\mathbf{1 0 0 )}$ & $\mathbf{1 4 8}(\mathbf{1 0 0})$ \\
\hline
\end{tabular}

\subsection{General Characteristics of Acute Lung Edema Cases with Severe Preeclampsia}

The case of pulmonary edema in pregnancy at Dr. Soetomo General Hospital mostly occurred in the maternal age group between 20-35 years, which was $85(56.1 \%)$ of 148 subjects with the youngest patient being 16 years and the oldest patient being 45 years old. Based on the method of arrival, most of the pulmonary edema subjects who came were referred patients, namely 141 subjects $(95.3 \%)$ and the number of subjects who was admitted to the ER directly was 7 subjects (4.7\%). Based on body mass index (BMI), 44 (30\%) subjects were included in the overweight BMI category, with the lowest BMI of $20 \mathrm{~kg} / \mathrm{m} 2$ and the highest BMI of $57.5 \mathrm{~kg} / \mathrm{m} 2$. A total of 120 subjects $(81.1 \%)$ cases of pulmonary edema occurred in the antepartum period, while the remaining $28(18.9 \%)$ occurred in the postpartum period. Most of the patients with acute pulmonary edema in pregnancy were multiparous patients, as many as 104 cases (70.3\%). Based on the classification of hypertension in pregnancy, most of the subjects suffered from preeclampsia, namely 116 subjects $(78.4 \%$ ) (Table 2).

Table 2. General characteristics of the subjects

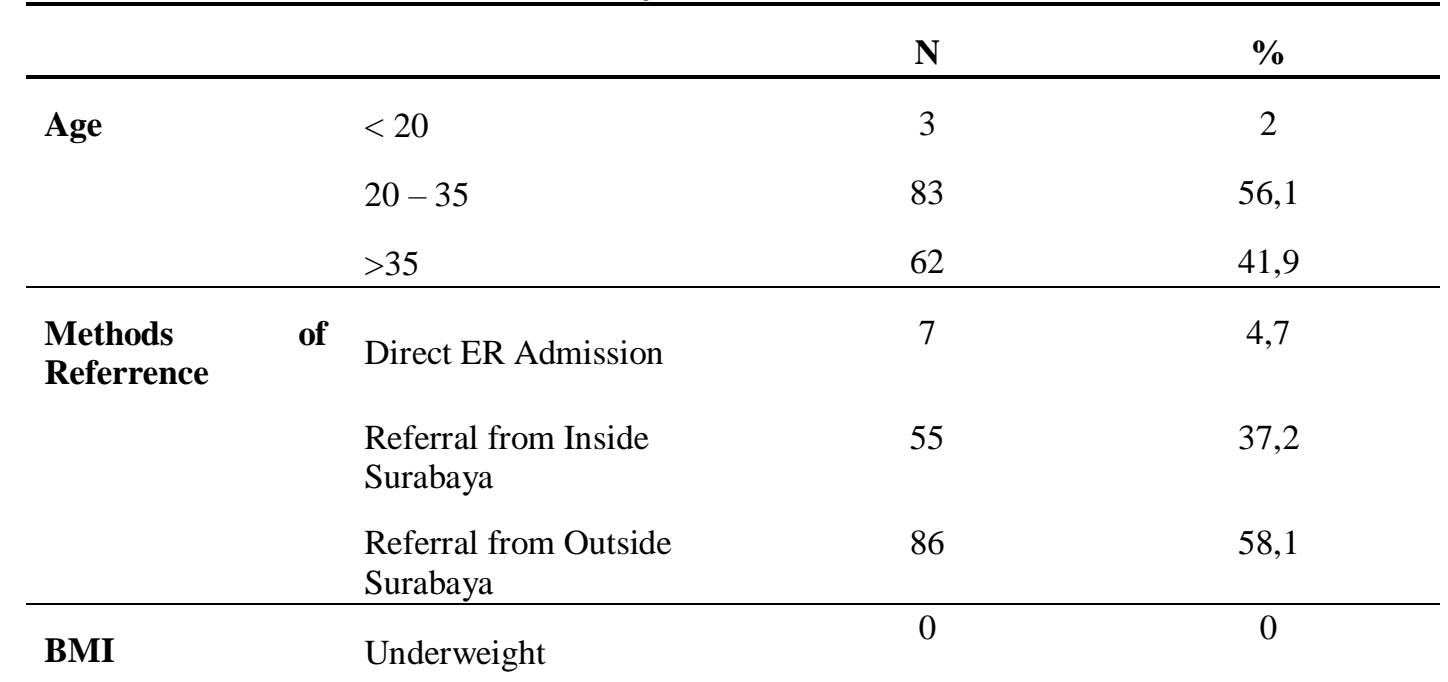




\begin{tabular}{|c|c|c|c|}
\hline & Normal & 25 & 16,9 \\
\hline & Overweight & 44 & 29,7 \\
\hline & Grade 1 Obesity & 33 & 22,3 \\
\hline & Grade 2 Obesity & 25 & 16,9 \\
\hline & Grade 3 Obesity & 21 & 14,2 \\
\hline Onset & $<28$ weeks & 8 & 5,4 \\
\hline & $28-34$ weeks & 46 & 31,1 \\
\hline & $>34$ weeks & 66 & 44,6 \\
\hline & Postpartum & 28 & 18,9 \\
\hline Classification & $\begin{array}{l}\text { Chronic } \\
\text { hypertension/superimpose } \\
\text { d preeclampsia } \\
\text { Preeclampsia } \\
\text { Eclampsia }\end{array}$ & $\begin{array}{c}29 \\
116 \\
3 \\
\end{array}$ & $\begin{array}{c}19,6 \\
78,4 \\
2 \\
\end{array}$ \\
\hline Parity & $\begin{array}{l}\text { Primipara } \\
\text { Multipara }\end{array}$ & $\begin{array}{c}44 \\
104\end{array}$ & $\begin{array}{l}29,7 \\
70,3\end{array}$ \\
\hline
\end{tabular}

We describe parametric data in severe preeclampsia patients with acute pulmonary edema in more detail regarding the lowest, highest, median, and mean scores in Table 3. The youngest maternal age was 16 years and the oldest was 45 years, with the mean maternal age was 31.7 years. The lowest BMI data is 20 $\mathrm{kg} / \mathrm{m} 2$ and the highest BMI is $57.5 \mathrm{~kg} / \mathrm{m} 2$, with an average BMI of $32.3 \mathrm{~kg} / \mathrm{m} 2$. From the results of the measurement of systolic blood pressure, the lowest value was $160 \mathrm{mmHg}$ and the highest value was 230 $\mathrm{mmHg}$, with a systolic mean of $169.5 \mathrm{mmHg}$. And from diastolic blood pressure, the lowest value was 100 $\mathrm{mmHg}$ and the highest value was $140 \mathrm{mmHg}$, with a diastolic mean of $107 \mathrm{mmHg}$.

Table 3 Maternal characteristics

\begin{tabular}{lccccc}
\hline & Mean & Median & Lowest & Highest & SD \\
\hline Age & 31,7 & 32,5 & 16 & 45 & 6,6 \\
BMI & 32,3 & 31,1 & 20 & 57,5 & 7,3 \\
SBP & 169,5 & 162 & 160 & 230 & 14,5 \\
DBP & 107 & 110 & 100 & 140 & 7,5 \\
\hline
\end{tabular}

\subsection{Maternal Outcomes}

From a total of 148 severe eclampsia patients with pulmonary edema, we found that the method of delivery in the subjects was dominated by abdominal delivery, with 91 (61.5\%) cases, while the remaining 57 $(38.5 \%)$ underwent vaginal delivery. Complications that occurred in the subjects included HELLP syndrome in $23(15.5 \%)$ cases, acute kidney injury (AKI) in $17(11.5 \%)$ cases, eclampsia in $3(2 \%)$ cases, and sepsis occurring in in $8(5.4 \%)$ cases. The maternal death of severe preeclampsia with acute lung edema was 12 cases $(8,1 \%)$.

Table 4. Maternal outcomes

Maternal Outcomes

\section{Delivery}

Vaginal

Abdominal
Total (\%)

$91(61,5)$ 


$\begin{array}{lc}\text { Complication } & \\ \text { HELLP syndrome } & 23(15,5) \\ \text { AKI } & 17(11,5) \\ \text { Eclampsia } & 3(2) \\ \text { Sepsis } & 8(5,4) \\ \text { Maternal death } & 12(8,1)\end{array}$

\subsection{Fetal outcomes}

The sex proportion of babies born to severe preeclampsia patients with pulmonary edema were $56(37.8 \%)$ male and $92(62.2 \%)$ female. Most babies were born with a weight of $2001-3000$ grams, which is $74(50 \%)$ babies. The average birth weight of babies was $2265 \pm 815$ grams, with the smallest birth weight of 200 grams and the largest birth weight of 4500 grams. The infant mortality rate in severe preeclampsia patients with pulmonary edema was found in $8(5.4 \%)$ cases (Table 5).

Table 5. Fetal outcomes

Characteristics

Sex

Male

Female

Birth weight (gram)

$\leq 500$

$501-1000$

$1001-2000$

$2001-3000$

$>3000$

Birth weight (gram)

Rerata \pm SD (gram)
Total

56

92

37,8

62,2

2,7

6,1

$\begin{array}{cc}41 & 27,7 \\ 74 & 50\end{array}$

$20 \quad 13,5$

(\%)

\begin{tabular}{ccc} 
Rerata \pm SD $($ gram $)$ & $2265 \pm 815$ & $\begin{array}{c}\text { Median: } 2200 \\
\text { Min : 200 } \\
\text { Max : } 4500\end{array}$ \\
\hline Apgar Score (First minute) & & \\
IUFD & 7 & 4,7 \\
$<4$ & 34 & 23 \\
$\geq 4$ & 107 & 72,3 \\
\hline Apgar Score (Fifth minute) & 8 & 5,4 \\
Death & 17 & 11,5 \\
$<4$ & 123 & 83,1 \\
$\geq 4$ &
\end{tabular}

\subsection{Corelation between severe preeclampsia and acute lung edema}

We performed an analysis based on the subgroup classification of hypertension in pregnancy, parity, mode of delivery, perinatal outcome, and maternal outcome. We obtained a significant $p$ value $(p<0.05)$ in the subgroup classification of hypertension, parity status and mode of delivery (Table 6).

Table 6. Corelation between severe preeclampsia and acute lung edema

\begin{tabular}{lccl}
\multicolumn{1}{c}{ Characteristics } & $\begin{array}{c}\text { Severe } \\
\text { preeclampsia } \\
\text { with acute lung } \\
\text { edema } \\
(\mathbf{\%})\end{array}$ & $\begin{array}{c}\text { Severe } \\
\text { preeclampsia } \\
\text { without acute } \\
\text { lung edema } \\
(\mathbf{\%})\end{array}$ & P \\
\hline $\begin{array}{l}\text { Classification } \\
\begin{array}{l}\text { Chronic hypertension/superimposed } \\
\text { preeclampsia }\end{array}\end{array}$ & $29(19,6)$ & $198(27,8)$ & \multirow{2}{*}{$0,033^{*}$} \\
Preeclampsia & $116(78,4)$ & $482(67,8)$ & \\
\hline
\end{tabular}




\begin{tabular}{|c|c|c|c|}
\hline Eclampsia & $3(2)$ & $31(4,4)$ & \\
\hline \multicolumn{4}{|l|}{ Parity } \\
\hline Primipara & $44(29,7)$ & $276(38,8)$ & \multirow{2}{*}{$0,037 *$} \\
\hline Multipara & $104(70,3)$ & $435(61,2)$ & \\
\hline \multicolumn{4}{|l|}{ Maternal Age } \\
\hline$>35$ tahun & $71(48)$ & $384(54)$ & \multirow{2}{*}{0,181} \\
\hline$<35$ tahun & $77(52)$ & $327(46)$ & \\
\hline \multicolumn{4}{|l|}{ Onset } \\
\hline Antepartum & $120(81,1)$ & 0 & \multirow{2}{*}{ N/A } \\
\hline Postpartum & $28(18,9)$ & 0 & \\
\hline \multicolumn{4}{|l|}{ Delivery } \\
\hline Vaginal & $57(38,5)$ & $460(64,7)$ & \multirow{2}{*}{$0,000^{*}$} \\
\hline Abdominal & $91(61,5)$ & $249(35,3)$ & \\
\hline \multicolumn{4}{|l|}{ Fetal outcome } \\
\hline IUFD & $7(4,7)$ & $39(5,5)$ & \multirow{4}{*}{0,698} \\
\hline Apgar Score minute $11-3$ & $34(23)$ & $176(24,7)$ & \\
\hline Apgar Score minute 1 4-6 & $49(33,1)$ & $201(28,3)$ & \\
\hline Apgar Score minute 1 7-9 & $58(39,2)$ & $295(41,5)$ & \\
\hline \multicolumn{4}{|l|}{ Creatinine } \\
\hline$>1,1 \mathrm{~g} / \mathrm{dL}$ & $70(47,3)$ & $304(42,8)$ & \multirow[t]{2}{*}{0,311} \\
\hline$\leq 1,1 \mathrm{~g} / \mathrm{dL}$ & $78(52,7)$ & $407(57,2)$ & \\
\hline \multicolumn{4}{|l|}{ Albumin } \\
\hline$<3 \mathrm{~g} / \mathrm{dL}$ & $51(34,5$ & $285(40,1)$ & \multirow[t]{2}{*}{0,202} \\
\hline$\geq 3 \mathrm{~g} / \mathrm{dL}$ & $97(65,5)$ & $426(59,9)$ & \\
\hline
\end{tabular}

*significant if $\mathrm{p}<0,05$

Furthermore, an analysis was carried out to determine the differences in characteristics and outcomes between subjects with mechanical ventilation and without mechanical ventilation (Tables 7 and 8). From the results of the analysis, there was a significant difference in length of stay $(p<0.001)$ between subjects with mechanical ventilation and subjects without mechanical ventilation.

Table 7. Maternal outcomes on with and without ventilator

Numerical variable

Maternal age

SBP (mmHg)

DBP (mmHg)

Albumin serum (g/dL)

Creatinine serum $(\mathrm{mg} / \mathrm{dL})$

\section{Ventilator} [median (min-max)]
Without ventilator

[median(min-max)]
$\mathbf{P}$

$\begin{array}{ccc}33(18-45) & 32(15-65) & 0,759 \\ 165(160-230) & 160(160-230) & 0,394 \\ 108(100-120) & 110(100-140) & 0,253 \\ 3,1(2,5-3,3) & 3(1,8-12,9) & 0,131 \\ 1,2(0,8-2,2) & 1,1(0-2,2) & 0,689 \\ 10(7-15) & 7(6-16) & 0,000^{*}\end{array}$

*significant if $\mathrm{p}<0,05$

Table 8 Characteristics of subjects with and without ventilator

\begin{tabular}{cccc}
\hline Categorical variable & Ventilator $[\mathbf{n}(\boldsymbol{\%})]$ & $\begin{array}{c}\text { Without ventilator }[\mathbf{n} \\
(\%)]\end{array}$ & $\mathbf{P}$ \\
\hline $\begin{array}{c}\text { Maternal age } \\
>35 \text { years }\end{array}$ & $34(49,3)$ & $421(53,3)$ & 0,522 \\
<35 years & $35(50,7)$ & $369(46,7)$ & \\
\hline Parity & $21(30,4)$ & $299(37,8)$ & 0,222 \\
Primipara & $484(69,6)$ & $491(62,2)$ & \\
Multipara & $56(78,9)$ & $64(83,1)$ & 0,982 \\
\hline Onset Edema & $15(21,1)$ & $13(16,9)$ & \\
Antepartum & & & $0,513^{\text {a }}$ \\
Postpartum &
\end{tabular}




\begin{tabular}{cccc}
\hline Yes & $1(1,5)$ & $33(4,2)$ & \\
No & $68(98,5)$ & $757(95,8$ & \\
Yes & $5(7,2)$ & $39(4,9)$ & $0,389^{\mathrm{a}}$ \\
No & $64(92,8)$ & $751(95,1)$ & \\
\hline Serum albumin < 3 g/dL & & & \\
Yes & $25(36,2)$ & $311(39,4)$ & 0,609 \\
No & $44(63,8)$ & $479(60,6)$ & \\
\hline Creatinine serum > 1,1 mg/dL & & & \\
Yes & $36(52,2)$ & $338(47,5)$ & 0,131 \\
No & $33(47,8)$ & $452(52,5)$ & \\
& & & \\
\hline
\end{tabular}

\section{Discussion}

Based on data obtained from medical records, from 2,968 deliveries carried out at Dr. Soetomo General Hospital in 2018-2019, the incidence of severe preeclampsia was found to be 859 cases (28.9\%). Of the 859 cases of severe preeclampsia, $148(17.2 \%)$ of them experienced acute pulmonary edema. It should be noted that as a tertiary education and referral center in eastern Indonesia, Dr. Soetomo general hospital only accepts referral patients from lower healthcare facilities on patients with varying complications, so this figure is relatively higher than other hospitals. The study of Wardhana et al. (2017) who also investigated the relationship between preeclampsia and the incidence of acute pulmonary edema in Dr. Soetomo Surabaya between 2013 and 2014 had an incidence of preeclampsia-eclampsia of 1106 cases (21\%) out of 5266 births. The high incidence reflects the condition of Dr. Soetomo General Hospital which is a tertiary referral hospital. Of the 1106 cases, 899 of them (81.3\%) were diagnosed with preeclampsia, while the remaining $113(10.2 \%)$ suffered from eclampsia. Of the 899 preeclampsia subjects, 62 of them (5.6\%) suffered from pulmonary edema (Wardhana, Dachlan and Dekker, 2018). The mean age of the patients in this study was $31.7+-6.6$ years. This study found that the incidence of pulmonary edema was slightly higher at age $<35$ years, which was $77(52 \%)$ of 148 cases of pulmonary edema. This result is different from the study by Liu et al. stated that the lowest risk of preeclampsia occurred in the 2529 year age group and the highest at the age $>40$ years (Liu et al., 2015). Sheen et al. also found that increasing age significantly increased the risk of developing pulmonary edema, heart failure, and acute renal failure in the preeclamptic patient group $(\mathrm{p}<0.01)$. Compared with a group of women aged 25-29 years, women aged 45-54 have a 2.28-fold risk of developing heart failure and pulmonary edema (Sheen et al., 2019).

The correlation between maternal age and the risk of pulmonary edema and preeclampsia can be explained by the abnormal adaptation of the cardiovascular system in pregnancy. Increasing maternal age is associated with decreased vascular compliance, endothelial function abnormalities, and an increase in the sympathetic nervous system which results in arterial stiffness and hypertension. Therefore, pregnant women with an older age tend to be more difficult to adapt to the physiological changes that occur during pregnancy. Increasing maternal age is also associated with increased vascular resistance in systemic blood vessels including the uterine arteries, thereby increasing the risk of hypertension in pregnancy, including preeclampsia (Cooke and Davidge, 2019). Hypertension has been shown to be a risk factor for pulmonary edema in pregnancy. The study by Pordeus et al. found that $62 \%$ of subjects with pulmonary edema suffered from hypertension, with entities in the form of preeclampsia, eclampsia, superimposed preeclampsia, and chronic hypertension (Pordeus et al., 2018). In addition, the study of Kubota-Sjogren et al. also reported the incidence of acute pulmonary edema in the postpartum period preceded by a hypertensive crisis (Kubota-Sjogren and Nelson-Piercy, 2015).

In this study, it was found that delivery data for patients with acute pulmonary edema were mostly dominated by abdominal deliveries, which were 91 (61.5\%) cases, compared to vaginal deliveries, which were 57 (38.5\%) cases. These results are similiar with the study of Amorim et al. who also found that $70 \%$ of cases of severe preeclampsia underwent abdominal delivery. The study also stated that women who had a vaginal delivery had a greater risk of developing postpartum bleeding and infection complications. In addition, vaginal delivery is also associated with an increased risk of oliguria and a very drastic increase in blood pressure, which can lead to various further complications, including hypertensive crisis and pulmonary edema. Subjects with abdominal delivery also have a risk of experiencing fluid overload due to the administration of excessive intravenous fluids during the procedure. This is in accordance with the results in this study which showed that $100 \%$ of subjects with pulmonary edema that occurred in the postpartum period underwent a previous abdominal delivery (Amorim et al., 2015) 
Of the 148 cases of acute pulmonary edema in pregnancy, perinatal morbidity and mortality were also found, including 7 (5\%) fetuses who died/IUFD and 34 (23\%) fetuses born with a first minute Apgar score $<4$. Study of Wardhana et al. reported that out of 50 births in cases of pulmonary edema with preeclampsia, 9 cases (18\%) of IUFD were obtained, 13 cases (26\%) were born with an Apgar score of 1-3, 8 cases (16\%) were born with an Apgar score of 4-6, and 20 cases (40\%) were born with an Apgar score of 7-9 (Wardhana, Dachlan and Dekker, 2018). The cohort study by O'Dwyer et al. reported a perinatal mortality rate of $21 \%$ in preeclamptic subjects with pulmonary edema (O’Dwyer, Gupta and Anthony, 2015). In cases of preeclampsia with complications of pulmonary edema, obstetrics and gynecology specialists generally do not have many alternatives, so they often have to decide to deliver babies in very premature conditions to save the mother's life (Wardhana, Dachlan and Dekker, 2018). The study of Pordeus et al. also added that acute pulmonary edema in the mother is not a direct cause of perinatal morbidity, but acute pulmonary edema is an indication of termination of pregnancy, and premature delivery of the fetus can increase perinatal/neonatal morbidity and mortality (Pordeus et al., 2018).

Table 5 shows that the average birth weight of infants in subjects with pulmonary edema was $2265 \pm$ 815 grams, which was classified as low birth weight. These results are consistent with a study by Proctor et al. who demonstrated that hypertension in pregnancy, including preeclampsia, was significantly associated with an increased risk of IUGR, in both singleton and multiple pregnancies. Hypertension in pregnancy is associated with various pathophysiologies previously described, one of which is systemic vasoconstriction which results in decreased uteroplacental blood flow, which can lead to IUGR (Proctor et al., 2019). In addition, preeclampsia and IUGR also occur based on similar pathophysiology, including failure of spiral artery remodeling by trophoblasts resulting in the formation of reactive oxygen species (ROS) (Surico et al., 2019).

Through subgroup analysis based on the classification of hypertensive disease in pregnancy consisting of chronic hypertension with superimposed preeclampsia, preeclampsia, and eclampsia, the proportion of preeclamptic subjects with pulmonary edema was significantly higher than subjects with chronic hypertension and superimposed preeclampsia and subjects with eclampsia. Pulmonary edema in preeclampsia patients can occur through various mechanisms, including hemodynamic changes that occur during pregnancy and the puerperium. The mechanism of 'auto-transfusion' in the mother after the delivery of the placenta causes pulmonary edema to occur in the puerperium. In preeclamptic subjects, there is an increase in toxic substrates from the chronically ischemic placenta. Increased toxic substrates and maternal catecholamine hormones result in increased systemic vascular resistance, endothelial damage, and increased left ventricular afterload, where the combination of these mechanisms results in left ventricular hypertrophy with abnormal ventricular filling (diastolic dysfunction), increased left ventricular end-systolic and diastolic volumes, myocardial ischemia, and ventricular arrhythmias and tachycardias. These factors can lead to heart failure as well as pulmonary edema in patients with severe preeclampsia. The incidence of pulmonary edema in patients with severe preeclampsia is also influenced by the degree of imbalance of angiogenic factors, the degree of increased systemic vascular resistance, the degree of myocardial relaxation disorder and ventricular filling abnormalities, the interaction between genetic factors and external factors, as well as the degree of cardiovascular abnormalities that may have existed previously (Bhorat, Naidoo and Moodley, 2017) (Keepanasseril et al., 2018). Theoretically, massive proteinuria and systemic inflammation also result in a decrease in serum albumin levels and a decrease in plasma oncotic pressure. Oliguria and elevated serum creatinine due to kidney damage also result in sodium and water retention, which also increases the susceptibility of patients with severe preeclampsia to pulmonary edema. However, our study did not find any difference in serum creatinine and albumin in patients with pulmonary edema and without pulmonary edema (Wardhana, Dachlan and Dekker, 2018).

Table 6 shows that there is a significant relationship on characteristics based on parity. This study showed that pulmonary edema was significantly more common in multiparous subjects. This result is in contrast to previous studies which found that the risk of pulmonary edema was higher in nulliparous women. Based on a study by Keepanasseril et al, nulliparous women with preeclampsia had a 5 times higher risk (95\% CI 1.06-23.41; $\mathrm{p}=0.041$ ) of developing acute pulmonary edema compared to multiparous women with preeclampsia (Keepanasseril et al., 2018). Nullipara itself has been known to be one of the risk factors for preeclampsia (Setiawan, Airlangga and Rahardjo, 2019). In addition, nulliparas are also associated with an increase in antiangiogenic mediators, so the risk of pulmonary edema in nulliparous women is higher than multiparous women (Keepanasseril et al., 2018).

Of all cases, complications were found in the form of HELLP syndrome, sepsis, AKI, and eclampsia. HELLP syndrome is known to be associated with multiorgan complications, including pulmonary edema, acute renal failure, disseminated intravascular coagulation, liver infarction, and liver hematoma with/without rupture. There have been no studies examining the statistical association of HELLP syndrome with pulmonary edema, but Mai et al. reported a case of HELLP syndrome complicated by pulmonary edema. HELLP syndrome is thought 
to be associated with pulmonary edema similar to that of preeclampsia because of the similar pathophysiology of HELLP syndrome and preeclampsia, where the pathophysiology of both is based on impaired immune tolerance resulting in trophoblast invasion of the fetus. In HELLP syndrome, there is an increase in anti-angiogenic factors, trophoblastic lesions, and abnormal gene expression in the placenta that is more massive than in preeclampsia, so HELLP syndrome is considered a variant of preeclampsia with more severe clinical signs and manifestations (Mai et al., 2018).

To date, we have not found a study that statistically examines the association between sepsis and pulmonary edema in pregnancy. In theory, Ma et al. explained that septic patients are also at risk for noncardiogenic pulmonary edema due to a systemic inflammatory response that causes damage to the capillary endothelium and alveolar epithelium, resulting in an increase in pulmonary capillary permeability. In addition, aggressive fluid therapy in septic patients can also increase the risk of pulmonary edema (Ma et al., 2017). A recommendation for the management of cases of sepsis in pregnancy also states that a crystalloid fluid bolus at a dose of $30 \mathrm{~mL} / \mathrm{kg}$ is excessive in cases of pregnancy with sepsis and may increase the risk of pulmonary edema due to the lower colloid osmotic pressure during pregnancy (Plante, Pacheco and Louis, 2003). 2019). The study of Marik et al. found that of all subjects with sepsis, only $23 \%$ of them were fluid responders (Marik and Bellomo, 2016). In individuals who are not fluid responders, aggressive fluid administration can result in third spacing (accumulation of edema fluid in the interstitial space) which leads to left ventricular diastolic dysfunction due to ventricular wall edema, and also results in pulmonary edema, cerebral edema, and intestinal edema with increased pressure. intra-abdominal, and increased mortality (Plante, Pacheco and Louis, 2019)

From the results of the analysis in table 8, it was found that subjects with mechanical ventilation had a statistically longer mean duration of treatment than subjects without mechanical ventilation. The reason that could underlie these results is that mechanically ventilated subjects had more severe clinical conditions than nonmechanically ventilated subjects, so that in general, mechanically ventilated subjects had a longer mean duration of treatment. This result is also similar to the study of Wardhana et al. who also had a longer mean duration of stay in mechanically ventilated subjects. The first choice of type of ventilation used in pulmonary edema patients with severe preeclampsia is non-invasive ventilation, but in patients with severe clinical conditions, especially in patients with decreased consciousness, invasive ventilation is a better option. An evidence-based case report by Hamada et al. stated that the provision of non-invasive positive-pressure ventilation can reduce mortality rates and reduce the need for invasive ventilation with a higher risk of complications. (Hamada et al., 2018; Wardhana, Dachlan and Dekker, 2018).

This study found no significant difference in serum creatinine and serum albumin levels between patients with severe preeclampsia with mechanical ventilation and without mechanical ventilation. In contrast, the study of Wardhana et al found a difference in serum albumin between patients with severe preeclampsia with mechanical ventilation and without mechanical ventilation. The need for mechanical ventilation is increased 5fold in patients with serum albumin less than $3 \mathrm{~g} / \mathrm{dL}$. Decreased serum albumin levels result in a decrease in colloid osmotic pressure which facilitates extravasation of intravascular fluid, thereby exacerbating the degree of pulmonary edema (Wardhana, Dachlan and Dekker, 2018).

\section{Conclusion}

The prevalence of acute pulmonary edema in patients with severe preeclampsia is $17.2 \%$, most of which occur antepartum with gestational age more than 34 weeks and most patients require intensive care with a ventilator.

\section{Acknowledgement}

We would like to acknowledge to all the staff in the department of obstetrics and gynecology of Dr. Soetomo General Hospital, Surabaya, Indonesia for all the help.

\section{References}

1. Amorim, M. M. R. et al. (2015) 'Maternal outcomes according to mode of delivery in women with severe preeclampsia: A cohort study', Journal of Maternal-Fetal and Neonatal Medicine, 28(6), pp. 654-660. doi: 10.3109/14767058.2014.928689.

2. Bhorat, I., Naidoo, D. P. and Moodley, J. (2017) 'Maternal cardiac haemodynamics in severe preeclampsia complicated by acute pulmonary oedema: A review', Journal of Maternal-Fetal and Neonatal Medicine, 30(23), pp. 2769-2777. doi: 10.1080/14767058.2016.1262842.

3. Cooke, C.-L. M. and Davidge, S. T. (2019) 'Advanced maternal age and the impact on maternal and 
offspring cardiovascular health', American Physiological Society, 317(2), pp. H397-H394. doi: 10.5281/zenodo.1477753.

4. Hamada, K. et al. (2018) 'Noninvasive Positive-Pressure Ventilation for Preeclampsia-Induced Pulmonary Edema: 3 Case Reports and a Literature Review', Case Reports in Obstetrics and Gynecology, 2018, pp. 1-6. doi: 10.1155/2018/7274597.

5. Karamchandani, K., Bortz, B. and Vaida, S. (2016) 'Acute pulmonary edema in an eclamptic pregnant patient: A rare case of Takotsubo syndrome', American Journal of Case Reports, 17, pp. 682-685. doi: 10.12659/AJCR.898937.

6. Keepanasseril, A. et al. (2018) '370. Risk factors of pulmonary edema among patients with preeclampsia : A case control study', Pregnancy Hypertension: An International Journal of Women's Cardiovascular Health, 13(2018), p. S138. doi: 10.1016/j.preghy.2018.08.409.

7. Kubota-Sjogren, Y. and Nelson-Piercy, C. (2015) 'Fulminant antenatal pulmonary oedema in a woman with hypertension and superimposed preeclampsia', BMJ Case Reports, 2015, pp. 2-5. doi: $10.1136 /$ bcr-2015-212751.

8. Liu, X. et al. (2015) '[Relationship Between Maternal Age and Hypertensive Disorders in Pregnancy]', Zhonghua Yi Xue Za Zhi, 95(1), pp. 19-22.

9. Ma, X. et al. (2017) 'Analysis of risk factors of secondary pulmonary edema during fluid resuscitation in sepsis patients', International Journal of Clinical and Experimental Medicine, 10(2), pp. 3445-3453.

10. Mai, C. et al. (2018) 'HELLP syndrome complicated by pulmonary edema: A case report', Open Medicine, 13(1), pp. 509-511. doi: 10.1515/med-2018-0075.

11. Marik, P. and Bellomo, R. (2016) 'A rational approach to fluid therapy in sepsis', British Journal of Anaesthesia, 116(3), pp. 339-349. doi: 10.1093/bja/aev349.

12. O’Dwyer, S. L., Gupta, M. and Anthony, J. (2015) 'Pulmonary edema in pregnancy and the puerperium: A cohort study of 53 cases’, Journal of Perinatal Medicine, 43(6), pp. 675-681. doi: 10.1515/jpm-2014-0206.

13. Plante, L. A., Pacheco, L. D. and Louis, J. M. (2019) 'SMFM Consult Series \#47: Sepsis during pregnancy and the puerperium', American Journal of Obstetrics and Gynecology, 220(4), pp. B2-B10. doi: 10.1016/j.ajog.2019.01.216.

14. Pordeus, A. C. B. et al. (2018) 'Acute pulmonary edema in an obstetric intensive care unit A case series study’, Medicine (United States), 97(28), pp. 1-5. doi: 10.1097/MD.0000000000011508.

15. Proctor, L. K. et al. (2019) 'Association between hypertensive disorders and fetal growth restriction in twin compared with singleton gestations', American Journal of Obstetrics and Gynecology, 221(3), pp. 251.e1-251.e8. doi: 10.1016/j.ajog.2019.04.022.

16. Setiawan, A. H., Airlangga, P. S. and Rahardjo, E. (2019) 'Komplikasi Edema Paru pada Kasus Preeklampsia Berat dan Eklampsia’, JAI (Jurnal Anestesiologi Indonesia), 11(3), p. 136. doi: 10.14710/jai.v11i3.23911.

17. Sheen, J.-J. et al. (2019) '318: Maternal age and preeclampsia outcomes', American Journal of Obstetrics and Gynecology, 220(1), pp. S222-S223. doi: 10.1016/j.ajog.2018.11.339.

18. Surico, D. et al. (2019) 'Preeclampsia and intrauterine growth restriction: Role of human umbilical cord mesenchymal stem cells-trophoblast crosstalk', PLoS ONE, 14(6), pp. 1-24. doi: 10.1371/journal.pone.0218437.

19. Wardhana, M. P., Dachlan, E. G. and Dekker, G. (2018) 'Pulmonary edema in preeclampsia: an Indonesian case-control study', Journal of Maternal-Fetal and Neonatal Medicine, 31(6), pp. 689695. doi: 10.1080/14767058.2017.1295442. 